\title{
Article
}

Doi 10.5943/mycosphere/8/6/11

Copyright $($ Guizhou Academy of Agricultural Sciences

\section{Aegis boa (Polyporales, Basidiomycota) a new neotropical genus and species based on morphological data and phylogenetic evidences}

\author{
Gómez-Montoya $\mathbf{N}^{1}$, Rajchenberg $\mathbf{M}^{2}$ and Robledo GL ${ }^{1,3^{*}}$ \\ ${ }^{1}$ Laboratorio de Micología, Instituto Multidisciplinario de Biología Vegetal, Consejo Nacional de Investigaciones \\ Científicas y Técnicas, Universidad Nacional de Córdoba, CC 495, CP 5000 Córdoba, Argentina \\ ${ }^{2}$ Centro de Investigación y Extensión Forestal Andino Patagónico (CIEFAP), C.C. 14, 9200 Esquel, Chubut and \\ Universidad Nacional de la Patagonia S.J. Bosco, Ingeniería Forestal, Ruta 259 km 14.6, Esquel, Chubut, Argentina \\ ${ }^{3}$ Fundación FungiCosmos, Av. General Paz 54, 4to piso, of. 4, CP 5000, Córdoba, Argentina.
}

Gómez-Montoya N, Rajchenberg M, Robledo GL. 2017 - Aegis boa (Polyporales, Basidiomycota) a new neotropical genus and species based on morphological data and phylogenetic evidences. Mycosphere 8(6), 1261-1269, Doi 10.5943/mycosphere/8/6/11

\begin{abstract}
The new genus, Aegis Gómez-Montoya, Rajchenb. \& Robledo, is described to accommodate the new species Aegis boa based on morphological data and phylogenetic evidences (ITS - LSU rDNA). It is characterized by a particular monomitic hyphal system with thick-walled, widening, inflated and constricted generative hyphae, and allantoid basidiospores. Phylogenetically Aegis is closely related to Antrodiella aurantilaeta, both species presenting an isolated position within Polyporales into Grifola clade. The new taxon is so far known from Yungas Mountain Rainforests of NW Argentina.
\end{abstract}

Key words - Grifola - Neotropical polypores - Tyromyces

\section{Introduction}

Polypore diversity of NW Argentina was reviewed by Robledo \& Rajchenberg (2007). The area is mainly dominated by the Yungas Rainforests, a tropical and subtropical cloud montane forest developed on the oriental slope along the Andes that, in Argentina, harbours 50\% of the country's biodiversity (Brown et al. 2001). Little information has been produced in the last years on this group of fungi, with the exception to those associated to the above timber-line Polylepis (Rosaceae) woodlands formation (Robledo et al. 2006) and some species in the Hymenochaetales (Amalfi et al. 2014). During surveys in this biogeographic formation specimens of a Tyromyces like species were found. On the basis of morphological features of their basidiomata relationships with Tyromyces chioneus (Fr.) P. Karst. or with Skeletocutis amorpha (Fr.) Kotl. \& Pouzar and their respective related species in the Tyromyces clade (Zhao \& Cui 2014, Wu et al. 2016) were expected. Nevertheless, molecular analyses suggested that these specimens group conforming an independent lineage strongly related to Antrodiella aurantilaeta (Corner) T. Hatt. \& Ryvarden.

The aim of this paper is to describe a new genus and species to accommodate these specimens, based on morphological and molecular studies.

\section{Materials \& Methods}




\section{Morphological studies}

Studied specimens are deposited at FCOS, Micoteca of FungiCosmos Foundation. Macroscopic observations follow Robledo \& Urcelay (2009). Microscopic observations were made in Melzer's reagent (IKI), 3\% potassium hydroxide $(\mathrm{KOH})$, phloxine, lactic acid Cotton Blue (CB; $\mathrm{CB}+=$ cyanophilous $)$ and Cresyl blue $(\mathrm{CrB} ; \mathrm{CrB}+=$ metachromatic $)$. Number of pores $/ \mathrm{mm}$ and measurements of microscopic structures were based on a sampling of thirty measures per structure $(\mathrm{n}=30)$. Basidiospore shape description follows Ferreira-Lopes et al. (2016). The following abbreviations are used for basidiospores measurements: $\bar{X}=$ arithmetic average, $Q=$ ratio length/width, $\bar{Q}=$ arithmetic average of $Q$. The hyphal system structure was analyzed using a $\mathrm{NaOH}$ in which handmade sections were incubated in warm $\left(50^{\circ} \mathrm{C}\right) \mathrm{NaOH} 3 \%$ solution during at least 24 hours and later mounted in $\mathrm{NaOH} 3 \%$ plus Congo red (Gómez-Montoya et al. 2017).

\section{DNA extraction, amplification and sequencing}

We followed Ferreira-Lopes et al. (2016) for DNA extraction from dry basidiomata. The primer pairs ITS8-F / ITS6-R (Dentinger et al. 2010) were used to amplify the ITS regions and LROR / LR5 (Vilgalys \& Hester 1990, Cubeta et al. 1991) to amplify the LSU regions. PCR conditions used followed Gómez-Montoya et al. (2017).

\section{Phylogenetic analyses}

ITS and LSU sequences newly generated in this study were deposited in GenBank (Table 1). DNA sequences were aligned using Muscle v.3.6 (Edgar 2004), later manually inspected and corrected using BioEdit V7.0.1 editor (Hall 1999). Indels were coded as binary characters using the software Fast Gap 1.2 (Borchsenius 2009). The best fit model of nucleotide evolution to the dataset was selected by AIC (Akaike Information Criterion) using jModelTest2 v.1.6 (Darriba et al. 2012) in the CIPRES Science Gateway platform (Miller et al. 2010). Bayesian analysis was performed by using MrBayes version 3.2.6 (Ronquist et al. 2011) with 5 million Metropolis-coupled Markov chain Monte Carlo (MCMCMC) generations with four chains, and two independent runs, the analysis was run for 5 million generations, after a burn-in of 20000 of the trees, nodes support was tested by posterior probabilities (PP), obtained from a 50\% majority rule consensus.

Individual datasets were combined in a Nexus file comprising 101 entries representing 82 putative species. Nodes with Bayesian Posterior Probability (BPP) $\geq 0.95$ were considered strongly supported, while nodes with $0.94 \geq \mathrm{BPP} \geq 0.7$ were considered moderately supported.

Table 1 List of taxa and sequences used in the phylogenetic analyses and their corresponding GenBank numbers. $\mathrm{O}=$ Outgroup; $\mathrm{T}=$ Type. Newly generated sequences are indicated in bold.

\begin{tabular}{llcc}
\hline \multirow{2}{*}{ Species } & \multirow{2}{*}{ Voucher reference } & \multicolumn{2}{c}{ GenBank Accesion Numbers } \\
\cline { 3 - 4 } Abortiporus biennis & FD-319 & KP135300 & LSU \\
\hline Aegis boa & Robledo 1384 & MF919318 & MF377539 \\
& Robledo 1685 (T) & MF377538 & MF377540 \\
Antrodia heteromorpha & Dai12755 & KP715306 & KP715322 \\
Antrodia hyalina & Miettinen_X1322 & JQ700283 & JQ700283 \\
Antrodia tanakae & Yuan1106 & KP715313 & KP715329 \\
Antrodiella aurantilaeta & Yuan5956 & KC485523 & KC485540 \\
& Yuan20 & FJ613653 & - \\
Antrodiella faginea & Voucher 2529 & KY769581 & - \\
Antrodiella foliaceodentata & Larsson11977 & JN710514 & JN710514 \\
Antrodiella ichnusana & MiettinenX1238 & JN710515 & JN710515 \\
Antrodiella lactea & MiettinenX131 & JN710516 & JN710516 \\
\hline
\end{tabular}


Table 1 Continued.

\begin{tabular}{|c|c|c|c|}
\hline \multirow{2}{*}{ Species } & \multirow{2}{*}{ Voucher reference } & \multicolumn{2}{|c|}{ GenBank Accesion Numbers } \\
\hline & & ITS & LSU \\
\hline Antrodiella nanospora & Yuan5755 & KC485531 & KC485549 \\
\hline Antrodiella romellii & MiettinenX154 & JN710520 & KC485543 \\
\hline Antrodiella semisupina & KHL11977 & JX109842 & JX109842 \\
\hline Antrodiella stipitata & strainFD-136 & KP135314 & KP135197 \\
\hline Bjerkandera adusta & BRNM 77194 & KT305935 & KT305935 \\
\hline Ceriporia lacerata & FP-55521T & KP135024 & KP135202 \\
\hline Ceriporia purpurea & $\mathrm{KKN}-223$ & KP135044 & KP135203 \\
\hline Ceriporia aurantiocarnescens & Yuan2066 & JX623902 & JX644042 \\
\hline \multirow[t]{2}{*}{ Ceriporiopsis aneirina } & Dai 12657 & KF845952 & KF845945 \\
\hline & НHB-15629 & KP135023 & KP135207 \\
\hline \multirow{2}{*}{ Ceriporiopsis gilvescens } & BRNM 667882 & FJ496685 & FJ496719 \\
\hline & Yuan 2752 & KF845953 & KF845946 \\
\hline Ceriporiopsis guidella & HUBO 7659 & FJ496687 & FJ496722 \\
\hline Ceriporiopsis pseudogilvescens & Niemelä 7447 & FJ496680 & FJ496700 \\
\hline Climacocystis borealis & KHL13318 & JQ031126 & JQ031126 \\
\hline Climacodon septentrionalis & AFTOL-ID 767 & AY85408 & AY684165 \\
\hline Coriolopsis caperata & LE(BIN)-0677 & $\mathrm{AB} 158316$ & AB158316 \\
\hline Dacryobolus montanus & Yuan5758 & KC344412 & KC344413 \\
\hline Daedalea quercina & Miettinen12662 & JX109855 & JX109855 \\
\hline Earliella scabrosa & PR1209 & JN165009 & JN164793 \\
\hline Fomitopsis pinicola & AFTOL-ID770 & AY854083 & AY684164 \\
\hline Gelatoporia subvermispora & strain_FD-354 & KP135312 & KP135212 \\
\hline Grammothelopsis subtropica & Cui9041 & JQ845096 & JQ845099 \\
\hline \multirow[t]{2}{*}{ Grifola frondosa } & zW-clarku005 & AY218415 & AY218413 \\
\hline & AFTOL-ID 701 & AY854084 & AY629318 \\
\hline Grifola sordulenta & AFTOL-ID562 & AY854085 & AY645050 \\
\hline Hornodermoporus martius & Cui4055 & KX081082 & KX081145 \\
\hline Hypochnicium lyndoniae & NL041031 & JX124704 & JX124704 \\
\hline Junghuhnia nitida & isolate 3135 & JN710560 & JN710560 \\
\hline \multirow[t]{2}{*}{ Loweomyces fractipes } & RP 197 & KP859304 & KP859309 \\
\hline & $\mathrm{X} 1250$ & JN710568 & JN710568 \\
\hline \multirow[t]{2}{*}{ Loweomyces spissus } & MCW 468/13 & KX378867 & KX378867 \\
\hline & MCW 471/13 & KX378868 & KX378868 \\
\hline Loweomyces tomentosus & MCW 366/12 & KX378870 & KX378870 \\
\hline Loweomyces wynneae & DD 846/08 & KX378865 & KX378865 \\
\hline Melanoporia nigra & isolate_X1735 & KC543172 & KC543172 \\
\hline Meripilus giganteus & FP-135344 & KP135307 & KP135228 \\
\hline Microporus xanthopus & Cui8242 & JX290074 & JX290071 \\
\hline Mycoacia fuscoatra & KHL13275 & JN649352 & JN649352 \\
\hline Mycoacia nothofagi & KHL13750 & GU480000 & GU480000 \\
\hline Mycorrhaphium adustum & isolate8024 & JN710573 & JN710573 \\
\hline Obba valdiviana & Gates FF484 & HQ659236 & HQ659236 \\
\hline Obba rivulosa & КСТС6892 & FJ496693 & FJ496710 \\
\hline Oligoporus balsameus & Cui8207 & KF699118 & KJ684974 \\
\hline Oligoporus lacteus & Cui12206 & KR605820 & KR605763 \\
\hline Oligoporus guttulatus & L-8050 & KC585360 & KC585189 \\
\hline \multirow[t]{2}{*}{ Oligoporus rennyi } & TN7389(H) & JX109849 & JX109849 \\
\hline & KEW57 & AY218416 & AF287876 \\
\hline
\end{tabular}


Table 1 Continued.

\begin{tabular}{|c|c|c|c|}
\hline \multirow{2}{*}{ Species } & \multirow{2}{*}{ Voucher reference } & \multicolumn{2}{|c|}{ GenBank Accesion Numbers } \\
\hline & & ITS & LSU \\
\hline Perenniporia medulla-panis & KHL11943 & JX109840 & JX109840 \\
\hline Perenniporiella neofulva & MUCL45091 & FJ411080 & FJ393852 \\
\hline Phanerochaete chrysosporium & BKM-F-1767 & HQ188436 & GQ470643 \\
\hline Phanerochaete velutina & LE_RUS298547 & KP994360 & KP994385 \\
\hline Phlebia acerina & Strain-FCUG568 & AF141615 & AF141615 \\
\hline \multirow[t]{2}{*}{ Phlebia rufa } & FCUG2397 & AF141628 & AF141628 \\
\hline & FBCC297 & LN611092 & LN611092 \\
\hline \multirow[t]{2}{*}{ Phlebia setulosa } & PH5105 & GU461313 & GU461313 \\
\hline & HHB-6891 & KP135382 & KP135267 \\
\hline Phlebia subserialis & FCUG 1434 & AF141631 & AF141631 \\
\hline \multirow[t]{2}{*}{ Phlebia tremellosa } & ES2008-2(GB) & JX109859 & JX109859 \\
\hline & F15198 & DQ384584 & DQ384584 \\
\hline Phlebia unica & KHL 11786 & EU118657 & EU118657 \\
\hline \multirow[t]{2}{*}{ Piloporia sajanensis } & HK 17250 & JX109853 & JX109853 \\
\hline & Manninen 2733a & HQ659239 & HQ659239 \\
\hline Podoscypha multizonata & Jahn 751012 & EU118663 & EU118663 \\
\hline Podoscypha venustula & LR_40821 & JX109851 & JX109851 \\
\hline Polyporus tuberaster & WD2382 & AB474086 & AB368104 \\
\hline \multirow[t]{2}{*}{ Pouzaroporia subrufa } & BRNM710172 & FJ496662 & FJ496724 \\
\hline & BRNM710164 & FJ496661 & FJ496723 \\
\hline Postia alni & MiettinenX1400 & KC595932 & KC595932 \\
\hline Postia caesia & НHВ-14891 & KC585376 & KC585206 \\
\hline Postia floriformis & Cui10292 & KM107899 & KM107904 \\
\hline Postia subcaesia & MiettinenX1340 & KC595944. & KC595944. \\
\hline \multirow[t]{3}{*}{ Rickiopora latemarginata } & isolate RP 56 & KU521768 & KU521768 \\
\hline & isolate RP 58 & KU521769 & KU521769 \\
\hline & isolate RP 110 & KU521770 & KU521770 \\
\hline Sebipora aquosa & Miettinen8680 & HQ659240 & HQ659240 \\
\hline Skeletocutis amorpha & Miettinen 110381 & FN907913 & FN907913 \\
\hline Steccherinum fimbriatum & KHL11905 & EU118668 & EU118668 \\
\hline Steccherinum ochraceum & KHL11902 & JQ031130 & JQ031130 \\
\hline \multirow[t]{2}{*}{ Stereum hirsutum $(\mathbf{O})$} & KUC20121102-16 & KJ668449 & KJ668300 \\
\hline & NBRC 6520 & AB733150 & AB733325 \\
\hline \multirow[t]{2}{*}{ Trametopsis aborigena } & Robledo1236 & KY655336 & KY655338 \\
\hline & Robledo1238 & KY655337 & KY655339 \\
\hline Trametopsis brasiliensis & Meijer 3637 & JN710510 & JN710510 \\
\hline \multirow[t]{2}{*}{ Trametopsis cervina } & PRM 900574 & AY684175 & AY855907 \\
\hline & TJV_93_216T & JN165020 & JN164796 \\
\hline \multirow[t]{2}{*}{ Tyromyces chioneus } & Cui 10225 & KF698745 & KF698756 \\
\hline & Miettinen $7487(\mathrm{H})$ & HQ659244 & HQ659244 \\
\hline Xanthoporus syringae & X339 & JN710606 & JN710606 \\
\hline
\end{tabular}

\section{Results}

\section{Molecular analyses}

ITS and LSU dataset comprised 101 taxa. Stereum hirsutum was used as outgroup. The alignment of the ITS region included 1024 positions including gaps, whereas LSU region included 880 positions including gaps. GTR $+\mathrm{I}+\mathrm{G}$ was chosen as the best-fit substitution model to the ITS 
dataset in the Bayesian Inference, with the following base frequencies A (0.2640), C (0.1829), G (0.2883), $\mathrm{T}(0.2648)$, proportion of invariable sites of 0.5020 and a gamma distribution shape parameter of 0.6030 . The nucleotide substitution rates estimated according to this model were $\mathrm{A} / \mathrm{C}=0.9728, \mathrm{~A} / \mathrm{G}=4.5720 \mathrm{~A} / \mathrm{T}=1.5535, \mathrm{C} / \mathrm{G}=0.5283, \mathrm{C} / \mathrm{T}=9.9187$ and $\mathrm{G} / \mathrm{T}=1.0000 . \mathrm{GTR}+\mathrm{I}+\mathrm{G}$ was chosen as the best-fit substitution model to the LSU dataset in the Bayesian Inference, with the following base frequencies A (0.2377), C (0.277), G (0.2199), $\mathrm{T}(0.3348)$, proportion of invariable sites of 0.2670 , and a gamma distribution shape parameter of 0.8700 . The nucleotide substitution rates estimated according to this model were $\mathrm{A} / \mathrm{C}=1.4525, \mathrm{~A} / \mathrm{G}=3.2371, \mathrm{~A} / \mathrm{T}=1.7110, \mathrm{C} / \mathrm{G}=0.6561$, $\mathrm{C} / \mathrm{T}=4.4622, \mathrm{G} / \mathrm{T}=1.0000$. The two independent runs of Bayesian analysis converged to stable values after 5000000 generations, a total of 20000 sampled trees were discarded as burn-in. The remaining trees were used to construct the 50\% majority-rule consensus tree (Figure 1).

Our phylogenetic analysis recovered a similar topology of recent works, where several major recognized clades are strongly supported (e.g. Binder et al. 2013, Zhao et al. 2014, 2015, Wu et al. 2016). The new specimens grouped in a strongly supported clade $(B P P=1.0)$ constituting an independent phylogenetic lineage that is described below as a new genus and species: Aegis boa. The new genus clustered together with Antrodiella aurantilaeta with a maximum support $(\mathrm{BPP}=1.0)$. Both species grouped with Grifola with a moderate support $(\mathrm{BPP}=0.79)$.

\section{Taxonomy}

Aegis Gómez-Montoya, Rajchenb. \& Robledo, gen. nov.

Mycobank: MB821875

Etymology - from Greek "aegis", shield of Pallas Athena, Greek goddess of wisdom and science, which was adorned with the Medusa Gorgon head. In reference to the general shield shape of the basidiomata and the hyphal system mimicking Medusa's head serpents.

Basidiomata annual, resupinate, effused-reflexed to pileate; pileal surface glabrous to tomentose, usually white to light ivory, azonate; pores round, 5-6 per $\mathrm{mm}$. Context thin, fibrous, white. Hyphal system monomitic with thin- to thick-walled clamped generative hyphae, metachromatic, IKI-. Basidia clavate, with four sterigmata. Basidiospores allantoid hyaline, thinwalled, IKI-.

Aegis boa Gómez-Montoya, Rajchenb. \& Robledo, sp. nov.

Figs 2-5

Mycobank: MB821876

Etymology - from Latin "boa"= large snake. In reference to the widened and constricted generative hyphae that recall Boa constrictor.

Holotype - Argentina, Salta, Dpto. Anta, Parque Nacional El Rey, Cerro El Chañar, $1950 \mathrm{~m}$ a. s. 1., $24^{\circ} 45^{\prime}$ 46.8" S, 64 $42^{\circ}$ ' 58.1" W, growing on dead fallen branch, 28 May 2007, Robledo 1685 (FCOS138, HOLOTYPE, ITS: MF377538, LSU: MF377540).

Basidiomata annual, resupinate to effused-reflexed, with a short reflexed portion; effused portion elliptical, up to $3 \times 1.5 \times 0.3 \mathrm{~cm}$, pileus elongated, applanate to triquetrous, up to $1 \mathrm{~cm}$ wide. Pileal surface white, light beige toward the base and against the substrate, concentrically sulcate, apparently glabrous but finely velutinate under the lens. Margin whitish to light grey, round, incurved upon drying, up to $0.5 \mathrm{~mm}$ thick in the effused part. Pore surface whitish. Pores rounded irregular, 5-6 per $\mathrm{mm}$; dissepiments entire. Context homogeneous, whitish to cream, fibrous, up to $0.1 \mathrm{~cm}$ thick. Tubes up to $0.2 \mathrm{~cm}$ long.

Hyphal system monomitic; generative hyphae with clamps, IKI-, CB-, metachromatic. The context mostly composed of thin-walled, hyaline hyphae, $2-6 \mu \mathrm{m}$ wide. The trama dominant by notoriously thick hyphae, 6-11 $\mu \mathrm{m}$ wide, hyaline and evenly thick-walled with a wide lumen to slightly yellowish and strongly thick-walled with a capillary lumen to subsolid; often presenting notorious wall-thickenings at the clamps, where lateral subsolid branches observed. Hyphae with strongly thickened walls occuring intercalary (between hyphae of walls not so thickened) or 
terminal, often presenting particular widening, inflated portions with lacunar lumen and constrictions. Dissepiment hyphae bearing very small, polymorphic and angular crystals.

Basidia clavate, with a basal clamp connection, hyaline, thin-walled, 14-16 $\times 4-5 \mu \mathrm{m}$, with four sterigmata. Basidiospores allantoid in equatorial lateral view, cylindrical, in equatorial adaxial view, smooth, hyaline, thin-walled, IKI-, (4.0-) 4.0-4.8(-5.0) $\times(1.0-) 1.2-2(-2.0) \mu \mathrm{m}, \bar{X}=4.2 \times$ $1.7 \mu \mathrm{m}, Q=2-4, \bar{Q}=2.6$.

Distribution - Known from Yungas Mountain Rainforests in NW Argentina.

Additional material studied - Argentina, Salta, Dpto. Sta. Victoria, Parque Nacional Baritú, Nogales, between Lipeo and Baritú towns, 1653 m. a. s. $1 ., 22^{\circ} 27^{\prime} 20.8^{\prime \prime} \mathrm{S}, 64^{\circ} 44^{\prime} 34.5^{\prime \prime} \mathrm{W}$, growing on dead fallen branch, 08 May 2007, Robledo 1384 (FCOS137).

\section{Discussion}

Aegis boa is characterized microscopically by a monomitic hyphal system with clamp connections and particular thick-walled hyphae that presents inflated and widened portions and constrictions, and allantoid basidiospores. Generative hyphae are thin-walled or, more commonly, have slightly thickened walls with a wide lumen. Many hyphae present particular thick-walled clamp connections from where a lateral ramification frequently occurs (Fig. 4). Widened hyphae have very thickened, yellowish walls, with a capillary lumen that closes in the constrictions. Inflated hyphae present moderately thickened walls and a lacunar lumen. Widened portions of generative hyphae are noticeably and easily observed when a thin section is mounted in the light microscope, giving the impression that the material presents vesicles. These hyphae are commonly terminal with rounded apices of thickened to subsolid walls; occasionally they occur in intercalary hyphae, between hyphae with slightly thickened walls. This combination of morphological characters does not match any other polypore genus described so far. In some way, macro- and micromorphological features of A. boa are reminiscent of Tyromyces chioneus and other Skeletocutis Kotl. \& Pouzar species in the 'Tyromyces clade', such as Skeletocutis amorpha. The typical crystals of Skeletocutis, and the diagnostic branched generative hyphae of T. chioneus are, though, absent in Aegis.

The phylogenetic reconstruction showed that the closest relative of A. boa is A. aurantilaeta. However, they present morphological differences. Antrodiella aurantilaeta develops orange to orange yellow basidiomata and present ellipsoid basidiospores (Corner 1989, Yuan 2013). In addition, $A$. aurantilaeta has a distinctly dimitic hyphal system with long and more or less uniform skeletal hyphae, and distributed in Aaia (Corner 1989, Dai 2012). Both species group with Grifola Gray with a moderately support $(\mathrm{BPP}=0.79)$. Grifola differs morphologically by developing typically multipileate, stitpitate or sessile basidiomata, and ovoid to ellipsoid basidiospores. Grifola was recovered recurrently with an isolated position in the phylogeny of the polypores (Hibbett \& Binder 2002, Binder et al 2013) constituting a family by itself (Justo et al. 2017). The closest relative of Grifola, A. aurantilaeta, was evidenced and confirmed recently (Yuan 2013, Justo et al. 2017).

Our phylogenetic analysis recovered the general topology of previous works, with Grifola, A. aurantilaeta and Aegis presenting an isolated position, here called 'Grifola' clade. Further studies, sampling of species and specimens, and more phylogenetic markers are needed to elucidate whether A. aurantilaeta may be congeneric with A. boa, and whether both species are part of Grifolaceae, currently including only just Grifola (Justo et al. 2017). The importance of the inclusion of species and specimens from tropical regions of the world for the interpretation of the phylogenetic scenario of the polypores is evidenced. 


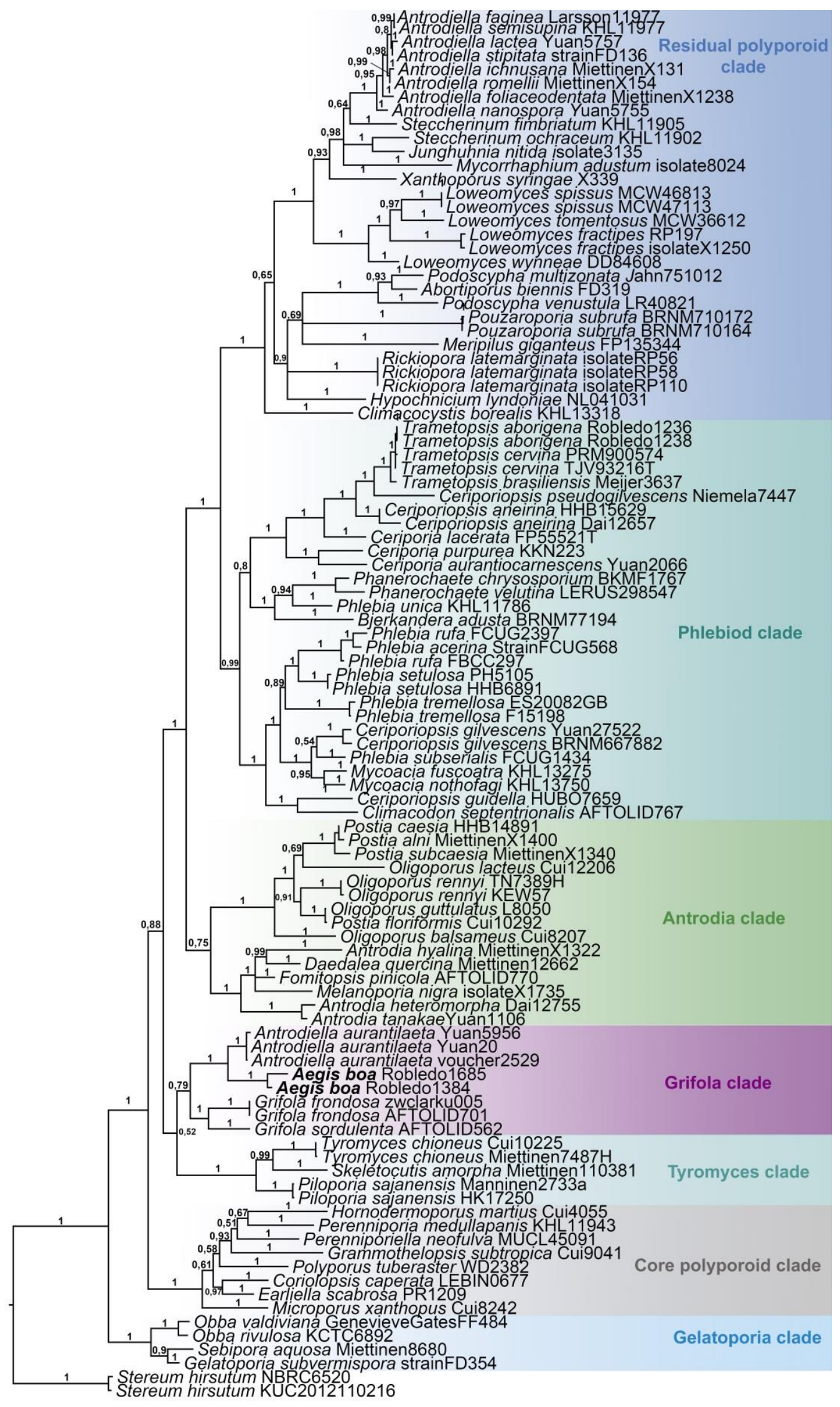

0.2

Figure 1 - Strict consensus tree from Bayesian inference of the combined ITS-LSU dataset illustrating the phylogenetic relationships of Aegis boa within Polyporales. The new species from which new sequences were obtained in this work are in boldface. 

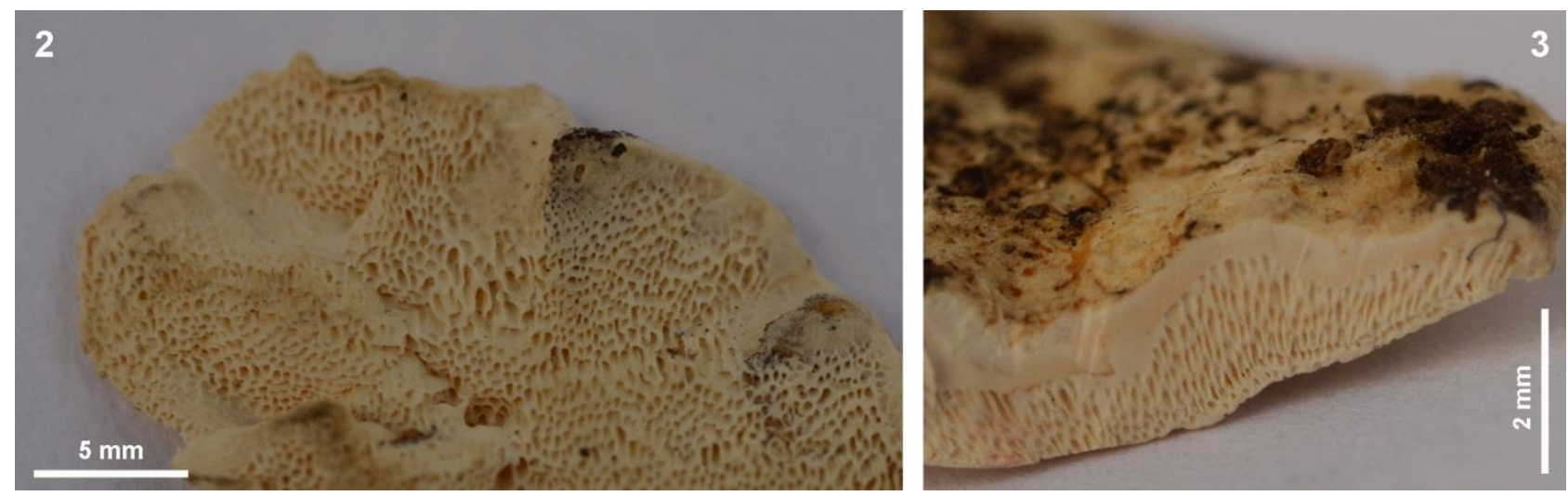

Figures 2-3 - Aegis boa, macroscopical features (Robledo 1685, FCOS138, Holotype). 2 General view of pore surface. 3 Longitudinal section, showing context and tubes. Pictures are copyright of G. Robledo.

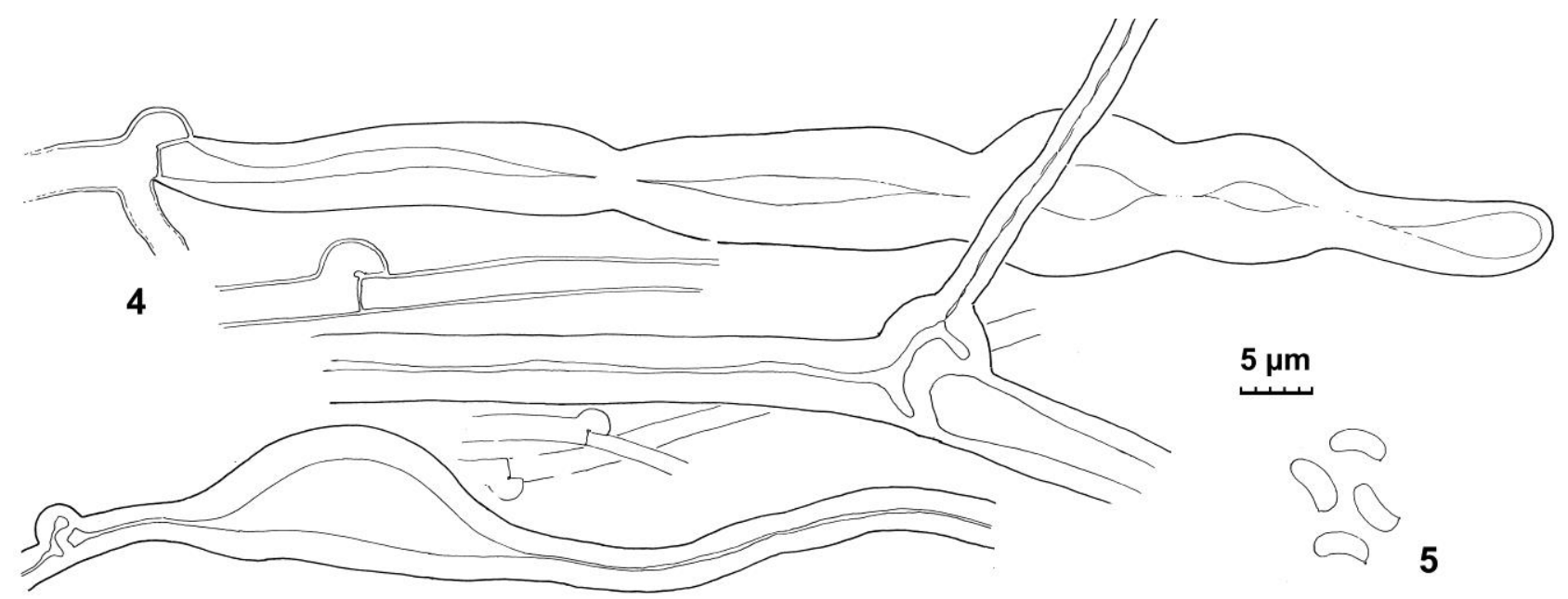

Figures 4-5 - Aegis boa, microscopical features (Robledo 1685, FCOS138, Holotype). 4 Generative hyphae. 5 Basidiospores equatorial lateral view. Drawings by G. Robledo.

\section{Acknowledgements}

Authors acknowledge the assistance of Consejo Nacional de Investigaciones Científicas y Técnicas (CONICET) and Universidad Nacional de Córdoba for the support facilities used in this work. Financial support was provided by FONCYT (PICT-2015-0830) to G. Robledo. Authors kindly acknowledge Idea Wild for their support with technical equipment; and L. Caeiro (CPA CONICET-UNC) and D. Franchi for their technical support.

\section{References}

Amalfi M, Robledo G, Decock C. 2014 - Fomitiporia baccharidis comb. nov., a little known species from high elevation Andean forests and its affinities within the neotropical Fomitiporia lineages. Mycological Progress 13, 1075-1087.

Binder M, Justo A, Riley R, Salamov A et al. 2013 - Phylogenetic and phylogenomic overview of the Polyporales. Mycologia 105, 1350-1373.

Borchsenius F. 2009 - FastGap 1.2. Department of Biosciences, Aarhus University, Denmark. Published online at: http://www.aubot.dk/FastGap_home.htm (accessed 1 June 2017).

Brown AD, Grau HR, Malizia LR, Grau A. 2001 - Bosques Nublados del Neotrópico. Costa Rica: Instituto Nacional de Biodiversidad (INBio). 
Dai YC. 2012 - Polypore diversity in China with an annotated checklist of Chinese polypores. Mycoscience 53, 49-80.

Corner EJH. 1989 - Ad Polyporaceae V. Beih Nov Hedw 96, 1-218.

Cubeta MA, Echandi E, Abernethy T, Vilgalys R. 1991 - Characterization of Anastomosis Groups of Binucleate Rhizoctonia species Using Restriction Analysis of an Amplified Ribosomal RNA Gene. Phytopathology 81, 1395-1400.

Darriba D, Taboada GL, Doallo R, Posada D. 2012 - jModelTest 2: more models, new heuristics and parallel computing. Nature Methods 9, 8-772.

Dentinger BTM, Margaritescu S, Moncalvo JM. 2010 - Rapid and reliable high-throughput methods of DNA extraction for use in barcoding and molecular systematics of mushrooms. Molecular Ecology Resources 10, 628-633.

Edgar Robert C. 2004 - MUSCLE: Multiple sequence alignment with high accuracy and high throughput, Nucleic Acids Research 32, 1792-97.

Ferreira-Lopes V, Robledo GL, Arduvino Reck M, Góes-neto A. et al. 2016 - Phylloporia spathulata sensu stricto and two new South American stipitate species of Phylloporia (Hymenochaetaceae). Phytotaxa 257, 133-148.

Gómez-Montoya N, Drechsler-Santos ER, Ferreira Lopes V, Tomšovský M. et al. 2017 - New insights on Trametopsis Tomšovský (Polyporales Gäum) based on phylogenetic evidences and morphological analyses of neotropical species. Phytotaxa 311, 155-166.

Hall TA. 1999 - BioEdit: a user-friendly biological sequence alignment editor and analysis program for Windows 95/98/NT. Nucleic Acids Symposium 41, 95-98.

Hibbett DS, Binder M. 2002 - Evolution of complex fruiting body morphologies in homobasidiomycetes. Proceedings of the Royal Society of London. Series B 269, 1963-1969.

Justo A, Miettinen O, Floudas D, Ortiz-Santana B et al. 2017 - A revised family-level classification of the Polyporales (Basidiomycota). Fungal Biology 121, 798-824.

Miller MA, Pfeiffer W, Schwartz T. 2010 - Creating the CIPRES Science Gateway for Inference of Large Phylogenetic Trees. In: SC10 Workshop on Gateway Computing Environments (GCE10).

Robledo GL, Rajchenberg M. 2007 - South American polypores: first annotated checklist from Argentinean Yungas. Mycotaxon 100, 5-9.

Robledo GL, Urcelay C. 2009 - Hongos de la madera en árboles nativos del centro de Argentina. Universidad Nacional de Córdoba, Córdoba.

Robledo GL, Urcelay C, Domínguez L, Rajchenberg M. 2006 - Taxonomy, ecology and biogeography of Polypores (Basidiomycetes) from Argentinian Polylepis woodlands. Canadian Journal of Botany 84, 1561-1572.

Ronquist F, Teslenko M, Van der Mark P, Ayres DL et al. 2011 - MRBAYES 3.2: efficient Bayesian phylogenetic inference and model choice across a large model space. Systematic Biology 61, 539-542.

Vilgalys R, Hester M. 1990 - Rapid genetic identification and mapping of enzymatically amplified ribosomal DNA from several Cryptococcus species. Journal of Bacteriology 172, 4238-4246.

Wu F, Zhou LW, Yuan Y, Tian XM. et al. 2016 - Cerarioporia cystidiata gen. et sp. nov. (Polyporales, Basidiomycota) evidenced by morphological characters and molecular phylogeny. Phytotaxa 280, 055-062.

Yuan HS. 2013 - Molecular phylogenetic evaluation of Antrodiella and morphologically allied genera in China. Mycological Progress 13, 353-364.

Zhao CL, Cui BK. 2014 - Phylogeny and taxonomy of Ceriporiopsis (Polyporales) with descriptions of two new species from southern China. Phytotaxa 164, 17-28.

Zhao CL, Cui BK, Song J, Dai YC. 2015 - Fragiliporiaceae, a new family of Polyporales (Basidiomycota). Fungal Diversity 70, 115-126.

Zhao CL, He XS, Wanghe KY, Cui BK. et al. 2014 - Flammeopellis bambusicola gen. et. sp. nov. (Polyporales, Basidiomycota) evidenced by morphological characters and phylogenetic analysis. Mycological Progress 13, 771-780. 